\title{
Formulation, Characterization and Evaluation of Behavioral Effects of Suspension and Effervescent Granules of Evolvulus alsinoides Linn. and Convolvulus pluricaulis Choisy
}

\author{
Garima Jain, Umesh K Pati** \\ Department of Pharmaceutical Sciences, Dr. Harisingh Gour Vishwavidyalaya (A Central University), Sagar, Madhya Pradesh, INDIA.
}

\begin{abstract}
Objectives: The objective of the present study was to formulate, characterize and evaluate herbal formulations of Evolvulus alsinoides and Convolvulus pluricaulis against scopolamine-induced behavioral disturbances for Alzheimer's disease. Methods: The herbal drugs were extracted using ethanol. The herbal suspension and effervescence granules were prepared using the extract and evaluated on rats. Scopolamine was used to induce behavioral and locomotor disturbances. Results: Results revealed that both the formulations were stable and effective in enhancing cognition against scopolamine-induced behavioral disturbance. The activity score of suspension of Evolvulus alsinoides and Convolvulus pluricaulis in the actophotometer were 128.19 and 110.23 while in effervescent granules of Evolvulus alsinoides and Convolvulus pluricaulis were 124.21 and 120.29 after 60 min, respectively. Suspension of Evolvulus alsinoides and Convolvulus pluricaulis reduced the fall off time to 94.18 and 102.03 while effervescent granules of Evolvulus alsinoides and Convolvulus pluricaulis reduced 98.01 and 98.16 after 30 min using the rota-rod, respectively. Suspension of Evolvulus alsinoides and Convolvulus pluricaulis reduce the activity of acetylcholinesterase as
\end{abstract}

19.10 and 18.01 Units/L while effervescent granules of Evolvulus alsinoides and Convolvulus pluricaulis reduce the activity of acetylcholinesterase as 17.69 and 14.36 Units/L. Conclusion: The formulations were significantly reduced locomotor activity using actophotometer, rotarod activity and the level of acetylcholinesterase. Thus, herbal suspension and effervescent granules of Evolvulus alsinoides and Convolvulus pluricaulis may be a safe alternative for Alzheimer's disease against scopolamine-induced behavioral disturbances.

Key words: Scopolamine, Rotarod, Actophotometer, Alzheimer's disease, Memory.

\section{Correspondence}

Dr. Umesh K Patil

Department of Pharmaceutical Sciences, Dr. Harisingh Gour Vishwavidyalaya (A Central University), Sagar, Madhya Pradesh, INDIA.

Phone no: +91 9425172165

Email: umeshpatil29@gmail.com

DOI: 10.5330/ijpi.2020.4.81

\section{INTRODUCTION}

Dementia is a clinical condition of progressive decline in cognition including memory, behavior and personality that results in loss of abilities to perform a basic activity of daily life and unable to perform proper bodily functions. ${ }^{1}$ The behavioral responses associated with dementia are agitation, apathy and rejection of care or aggression. ${ }^{2}$ Other behavior and psychological problems in dementia are motor behavior, hallucination, alteration in sleep and elation. ${ }^{3}$ These symptoms have seen in around $90 \%$ of people with dementia. ${ }^{4}$ Alzheimer's disease (AD) is a neurodegenerative disorder and the most common cause of dementia. ${ }^{5,6}$ Dementia is often associated with other neurodegenerative disorders also including Parkinson's disease and Huntington's disease. The cluster of behavioral and psychological symptoms led to a deficiency of acetylcholine (ACh) level in the brain. ${ }^{8}$ Acetylcholinesterase (AChE) is an enzyme responsible for the hydrolysis of ACh. Thus, an AChE inhibitor may help to improve cognition and approved for relief in AD. ${ }^{9}$ The researchers are still in a search for an effective and safe medicine for the cure of memory disorders.

Ayurveda is believed to be the oldest alternative system of medicine in the world that is recognized as the comprehensive health-care system and as alternative medicine. ${ }^{10}$ Ayurveda is an ancient system of medicine in India including medicinal plants in the treatment of several diseases. Evolvulus alsinoides L. (EA) belongs to family Convolvulaceae, it is an ancient and well-known plant containing numerous medicinal properties. ${ }^{11}$ EA was adopted as the alien plant of Asia based on its geographical distribution, laboratory analyses and its biological uses; it was also incorporated in pharmacopeias. ${ }^{12}$ This plant is popularly known for its therapeutic use in bronchitis, cognition impairment, asthma, etc. It is used as a brain tonic against neurological disorders and amnesia. ${ }^{13}$ Convolvulus pluricaulis (CP) is a traditional herbal plant, it is a wellknown herb in India and used as a nerving tonic for a long time ago. ${ }^{14}$ All parts of this plant possess medicinal and therapeutic properties; it has been used traditionally for its antiepileptic, antioxidant, sleepinducing, anticancerous, antianxiety and cough relieving properties. ${ }^{15,16}$ Ayurvedic herbal drugs and formulations have been used to enhance memory and slow down the progressive decline in cognition. ${ }^{17} \mathrm{ACh}$ plays a role in the regulation of behaviors and scopolamine is expected to affect locomotion, avoidance and rearing. ${ }^{18}$ Scopolamine increases locomotor activity during a stress condition. Induction of motor activity may help to determine the effect of the drug on animal's behavior; however, it is affected by factors such as the strain of animals, changing environmental conditions, light-dark chamber, social isolation and stressful conditions. ${ }^{19,20}$ It has reported that giving hypnotics to the patients may help a person with dementia for enhancing cognition and also treating anxiety. In the present study, the herbal formulations were prepared to enhance the efficacy of herbal drugs and evaluated against scopolamine-induced behavioral disturbance. 


\section{MATERIALS AND METHODS}

\section{Plants material}

C. pluricaulis and E. alsinoides were collected from area adjoining to University campus. It was authenticated in the Department of Botany, Dr. Harisingh Gour Vishwavidyalaya, Sagar (M.P.).

Herbarium no. for C. pluricaulis: Bot/H/05/111/04

Herbarium no. for E. alsinoides: Bot/H/05/111/01

\section{Extraction of C. pluricaulis and E. alsinoides using soxhlet assembly}

The whole plant of C. pluricaulis and E. alsinoides were dried, grounded and defatted with petroleum ether for a day then inserted in a soxhlet apparatus with ethanol (90\%) individually for $72 \mathrm{hrs}$ at $55^{\circ} \mathrm{C}$. The collected extracts were concentrated and proceed for next step.

\section{Estimation of Total alkaloids content}

Preparation of drug sample: Small parts of the extracts were dissolved in $2 \mathrm{~N} \mathrm{HCl}$ and filtered separately. $1 \mathrm{ml}$ of both solutions were transferred to two different separating funnel and washed with $10 \mathrm{ml}$ chloroform (3 times). $\mathrm{pH}$ of solutions was adjusted to neutral with $0.1 \mathrm{~N} \mathrm{NaOH}$ solution. $5 \mathrm{ml}$ of Bromocresol green (BCG) solution and $5 \mathrm{ml}$ of phosphate buffer ( $\mathrm{pH}$ 4.7) were added with shaking. Formed complex were extracted with $5 \mathrm{ml}$ chloroform by vigorous shaking. Then chloroform layer were collected in a $10 \mathrm{ml}$ volumetric flask and volume makes upto mark with chloroform.

Preparation of BCG solutions: $69.8 \mathrm{mg}$ BCG was heating with $3 \mathrm{ml}$ of $2 \mathrm{~N} \mathrm{NaOH} .5 \mathrm{ml}$ distilled water was added to dissolve it then diluted upto $1000 \mathrm{ml}$ with distilled water.

Preparation of Standard solution and standard curve: $100 \mu \mathrm{g} / \mathrm{ml}$ atropine solution was prepared. Measured aliquots $(0.2,0.4,0.6,0.8$, 1 and $1.2 \mathrm{ml}$ ) were transferred to different separating funnels. $5 \mathrm{ml}$ pH 4.7 phosphate buffers and $5 \mathrm{ml}$ BCG solution were added and 5 $\mathrm{ml}$ of chloroform was added. The chloroform layer was collected in a $10 \mathrm{ml}$ volumetric flask and makeup the volume with chloroform. The absorbance was measured at $470 \mathrm{~nm}$ against blank. Total alkaloid content was determined in term of $\mathrm{mg}$ atropine equivalent per $100 \mathrm{~g}$ extract (Figure 1). ${ }^{21}$

\section{Preparation of herbal suspensions}

Excipients such as Tween $80(0.1 \%)$, sodium CMC $(0.5 \mathrm{~g})$, sodium benzoate $(0.5 \mathrm{~g})$, lemon oil $(0.5 \mathrm{ml})$, sweetening agent $(0.1 \mathrm{~g})$ and water $(100 \mathrm{ml})$ with ethanolic extracts of EA and CP were mixed individually. All ingredients were triturated separately to form a fine powder. The

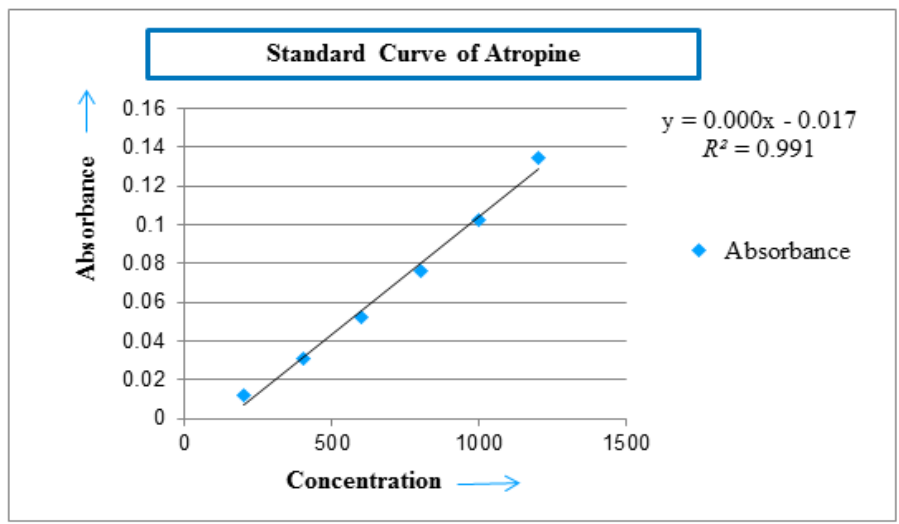

Figure 1: Standard curve of Atropine for determination of Total Alkaloids Content. extracts were mixed in water and tween-80 and then mixed to triturated substances. CMC, sweetening agent, flavoring agent and sodium benzoate were mixed. ${ }^{22}$

\section{Preparation of herbal effervescent granules}

Effervescent granules were prepared by a wet granulation technique. The excipients were polyvinyl pyrrolidone (PVP, $24 \mathrm{mg})$, talc $(7.5 \mathrm{mg})$, magnesium stearate $(3.75 \mathrm{mg})$, sweetening agent $(5 \mathrm{mg})$, polyethylene glycol (PEG, $12 \mathrm{mg}$ ), citric acid (79.33 mg), tartaric acid (158.66 mg) and sodium bicarbonate $(69.71 \mathrm{mg})$. Extracts and other ingredients were triturated separately followed by subsequent addition of PVP, talc powder, PEG, sodium bicarbonate, citric acid, tartaric acid, sweetening agent and magnesium stearate then sufficient quantity of alcohol was added to form a lumpy mass which was then passed through sieve no. 18 to form granules. Granules were dried and stored in an airtight container. ${ }^{23}$

\section{Characterization of herbal suspension Physical parameters and ph determination}

Nature, color, odor and texture of herbal suspensions were determined by physical evaluation. The $\mathrm{pH}$ of herbal suspensions were determined using a $\mathrm{pH}$ meter. ${ }^{24}$

\section{Sedimentation volume}

It was determined by placing a measured volume of suspension in a graduated cylinder (as Initial Height) in an undisturbed state for a certain period and note that the volume of the sediment which is expressed as ultimate height under standard condition. ${ }^{25}$

\section{Redispersibility}

It was determined through settled closed mouth measuring cylinder. The cylinder was inverted at $180^{\circ}$ and the number of inversions was noted to restore a homogeneous suspension. ${ }^{26}$

\section{Viscosity and Rheology (F)}

The viscosity of the sample was determined using Oswald Viscometer. However, rheology is the required time of the suspension to flow in the measured pipette.

\section{Particle size}

The particle size of herbal suspension was determined using an optical microscope.

\section{Stability studies}

Stability of suspension decreases due to crystal growth, which was determined at different temperatures i.e. $4^{\circ} \mathrm{C}, 25^{\circ} \mathrm{C}$ and $47^{\circ} \mathrm{C}$ (Table 1). ${ }^{22}$

\section{Characterization of herbal effervescent granules Physical parameters}

Nature, color, odor and texture of the herbal granules were determined by physical evaluation. The $\mathrm{pH}$ of the herbal suspension was determined using a $\mathrm{pH}$ meter.

\section{Angle of repose}

The funnel method was used to perform the test and calculated as follows:

$$
\theta=\tan -1(\mathrm{~h} / \mathrm{r})
$$

\section{Bulk density}

It is the ratio of the total mass of powder to the bulk volume of powder.

$$
\mathrm{Db}=\mathrm{m} / \mathrm{Vo}
$$


Where, m: Mass of the blend, Vo: Untapped Volume

\section{Tapped density}

Tapped density is the ratio of the mass of powder to the tapped volume. Tapped volume is the volume occupied by the same mass of the powder after a standard tapping of a measure.

$$
\mathrm{Dt}=\mathrm{m} / \mathrm{Vi}
$$

Where, m: Mass of the blend, Vi: Tapped Volume

\section{Carr's index}

It is a measure of the propensity of the granules to be compressed and determined from the bulk and tapped densities.

$$
\text { Carr's Index }=\frac{D t-D b}{D t} \times 100
$$

Where, Dt: Tapped density, Db: Bulk density

\section{Hausner's ratio}

It is an indirect index of ease of powder flow, calculated by the following formula.

$$
\text { Hausner's Ratio }=\text { Tapped density } / \text { Bulk density }
$$

\section{Effervescent cessation time}

$100 \mathrm{ml}$ of distilled water was taken in a beaker and one dose of effervescent granules was poured into the beaker then effervescent

\begin{tabular}{|c|c|c|c|c|}
\hline Sn & Sample & $\begin{array}{l}\text { Time duration } \\
\text { (h) }\end{array}$ & $\begin{array}{c}\text { Temperature } \\
\left({ }^{\circ} \mathrm{C}\right)\end{array}$ & $\begin{array}{c}\text { Crystal } \\
\text { formulation }\end{array}$ \\
\hline \multirow[t]{11}{*}{1.} & EA & 24 & 4 & No \\
\hline & & 24 & 25 & No \\
\hline & & 24 & 47 & No \\
\hline & & 48 & 4 & No \\
\hline & & 48 & 25 & No \\
\hline & & 48 & 47 & No \\
\hline & & 72 & 4 & No \\
\hline & & 72 & 25 & No \\
\hline & & 72 & 47 & No \\
\hline & & 3 months & RT & No \\
\hline & & 6 months & RT & No \\
\hline \multirow[t]{11}{*}{2.} & $\mathrm{CP}$ & 24 & 4 & No \\
\hline & & 24 & 25 & No \\
\hline & & 24 & 47 & No \\
\hline & & 48 & 4 & No \\
\hline & & 48 & 25 & No \\
\hline & & 48 & 47 & No \\
\hline & & 72 & 4 & No \\
\hline & & 72 & 25 & No \\
\hline & & 72 & 47 & No \\
\hline & & 3 months & RT & No \\
\hline & & 6 months & RT & No \\
\hline
\end{tabular}
cessation time and effervescent production was observed.

\section{Table 1: Effect of temperature on stability of herbal suspensions.}

Determination of memory using behavioral models Acute toxicity study

The acute toxicity study was performed for both the formulations as per OECD guidelines 423 . Three animals were selected for each dose group i.e. 5, 50, 300 and $2000 \mathrm{mg} / \mathrm{kg}$ body weight, given p.o. Different activities of animals (change in fur color, behavior, any lethargic sign, etc.) were observed in the first $4 \mathrm{~h}$ after $10 \mathrm{~h}$ and once a day daily for 14 days.

\section{Experimental animals}

Wistar rats of either sex weighing 150-200g were selected for the study. The animals were procured from the animal house of the institute. The experimental protocols were approved by the Institutional animal ethics committee (IAEC No. 379/GO/ReBi/S/01/CPCSEA, Reference no. 379/CPCSEA/IAEC-2018/035) after scrutinization. The animals were fed with standard pelleted diet and water ad libitum. The animals were acclimatized to the laboratory condition before experiment. The animals were fasted for at least $24 \mathrm{~h}$ before treatment. The animals were divided into nine groups i.e. Group 1: Negative control group $(0.2 \%$ v/v Tween-80), Group 2: Positive control group (scopolamine, $0.3 \mathrm{mg} /$ kg; i.p), Group 3: Standard group (piracetam, $100 \mathrm{mg} / \mathrm{kg}$; oral), Group 4: Ethanolic extract of EA (200 mg/kg; oral), Group 5: Suspension of EA (200 mg/kg; oral), Group 6: Effervescent granules of EA (200 mg/ $\mathrm{kg}$; oral), Group 7: Ethanolic extract of CP (200 mg/kg; oral), Group 8: Suspension of CP (200 mg/kg; oral), Group 9: Effervescent granules of CP $(200 \mathrm{mg} / \mathrm{kg}$; oral $)$ each group contained six animals. The animals were treated for 15 days, however, scopolamine was administered to the animals on the $9^{\text {th }}$ day, intraperitoneally. ${ }^{27}$

\section{Determination of animal's behavior using actophotometer}

Actophotometer was used to determine animals' locomotor behavior. The basal activity was evaluated by placing animals for $5 \mathrm{~min}$. The animals were treated with the test drug and scoring was performed after $30 \mathrm{~min}$ and $1 \mathrm{~h}$. The index of CNS depression was taken as the decreased activity score (Table 2$)^{28}$

\section{Rota-rod performance of animals}

Animals were placed on a rod rotating at $20-25 \mathrm{rpm}$ speed. The animals that remained stable and showed their ability were on the revolving rod

Table 2: Effect of EA and CP formulations on activity score in actophotometer method.

\begin{tabular}{cccc|}
\hline & \multicolumn{3}{c}{ Mean score in 5 min } \\
\cline { 2 - 4 } & Basal & $30 \mathrm{~min}$ & $60 \mathrm{~min}$ \\
\hline Group 1 & $350.23 \pm 12.29$ & $354.22 \pm 7.38$ & $352.02 \pm 9.30$ \\
Group 2 & $341.48 \pm 9.39$ & $397.27 \pm 9.04$ & $426.81 \pm 11.39$ \\
Group 3 & $340.02 \pm 10.27$ & $244.36 \pm 8.99^{* * *}$ & $105.26 \pm 12.39^{* * *}$ \\
Group 4 & $354.18 \pm 11.27$ & $329.52 \pm 9.01$ & $308.08 \pm 8.03^{* *}$ \\
Group 5 & $348.83 \pm 12.28$ & $252.36 \pm 6.49^{* * *}$ & $128.19 \pm 9.30^{* * *}$ \\
Group 6 & $345.26 \pm 11.02$ & $250.88 \pm 11.93^{* * *}$ & $124.21 \pm 13.20^{* * *}$ \\
Group 7 & $344.74 \pm 8.38$ & $324.11 \pm 10.49$ & $309.14 \pm 11.03^{* *}$ \\
Group 8 & $343.37 \pm 9.38$ & $247.29 \pm 8.39^{* * *}$ & $110.23 \pm 9.30^{* * *}$ \\
Group 9 & $344.32 \pm 10.28$ & $253.09 \pm 7.39^{* * *}$ & $120.29 \pm 8.38^{* * *}$ \\
\hline
\end{tabular}

Data are represent as mean \pm SEM $(n=6)$ and one-way analysis of variance (ANOVA) followed by Dunnett test for multiple column comparison. $* P<0.05$, ${ }^{* *} P<0.01$ and $* * * P<0.001$ were considered to be less significant, significant and more significant when all groups were compared with control. 
for 5 min were selected for the study. The fall-off time was recorded prior and post-drug administration (Table 3 ). ${ }^{29}$

\section{Determination of AChE inhibitory activity}

The activity was determined through 96-well microplate assay according to the method of Ellman et al. $1961 .^{30}$ In this method, thiocholine produced by AChE reacts with 5,5'-dithiobis(2-nitrobenzoic acid) (DTNB) to form a colorimetric $(412 \mathrm{~nm})$ product. Acetylthiocholine iodide $(15 \mu \mathrm{M})$ in $25 \mu \mathrm{l}$ was added into a microplate well along with the addition of DTNB $(125 \mu \mathrm{l})$ in $50 \mathrm{mM}$ of Tris/ $\mathrm{HCl}(\mathrm{pH} 8)$ with $\mathrm{NaCl}$ $(0.1 \mathrm{M})$ and $\mathrm{MgCl}_{2} \cdot 6 \mathrm{H}_{2} \mathrm{O}(0.02 \mathrm{M})$. Further, $50 \mu \mathrm{l}$ of bovine albumin fraction $\mathrm{V}(0.1 \%), 25 \mu \mathrm{l}$ of test drugs dissolved in methanol and diluted in Tris/ $\mathrm{HCl}(50 \mathrm{mM}, \mathrm{pH} 8)$ at concentrations of 1.25, 12, 20, 40, 80, 160, $320 \mu \mathrm{g} / \mathrm{ml}$ were added into well. The absorbance was measured after 2 min of incubation at room temperature; the initial absorbance was taken at $412 \mathrm{~nm}$ and after $10 \mathrm{~min}$, the final measurement was taken. All the analysis was performed in triplicate. ${ }^{31}$ The AChE activity was calculated using the following formula (Table 4):

$$
\operatorname{AChE} \text { Activity }(\text { Units } / \mathrm{L})=\frac{\left(\mathrm{A}_{412}\right) \text { Final- }\left(\mathrm{A}_{412}\right) \text { Initial }}{\left(\mathrm{A}_{412}\right) \text { Calibrator }-\left(\mathrm{A}_{412}\right) \text { Blank }} \times n \times 200
$$

$200=$ Equivalent activity (Units/L) of the calibrator when assayed is read at $2 \mathrm{~min}$ and $10 \mathrm{minn}=$ dilution factor

$\left(\mathrm{A}_{412}\right)_{\text {Calibrator }}=$ Absorbance of the calibrator at $10 \mathrm{~min}$

$\left(\mathrm{A}_{412}\right)_{\text {Blank }}=$ Absorbance of the blank at $10 \mathrm{~min}$

\section{Histopathology of Brain Tissues}

Histopathological analysis of brain specimens was performed and the obtained tissue sections were de-paraffinized and stained with Hematoxylin and Eosin stain examination (Figure 2). ${ }^{32}$

\section{Statistical analysis}

The results were presented as the mean \pm S.E.M. and one-way analysis of variance (ANOVA) using GraphPad Prism 5 followed by Dunnett test for multiple comparisons.

\section{RESULTS}

Percentage yield of ethanolic extract of CP and EA was $8.43 \%(w / w)$ and $12.68 \%(w / w)$ respectively. Total alkaloids content of ethanolic extract

Table 3: Effect of EA and CP formulations on fall off time in rotarod.

\begin{tabular}{ccc}
\hline \multirow{2}{*}{ Groups } & \multicolumn{2}{c}{ Mean score in 5 min } \\
\cline { 2 - 3 } & Basal & $30 \mathrm{~min}$ \\
\hline Group 1 & $223.38 \pm 13.39$ & $229.66 \pm 10.35$ \\
Group 2 & $226.39 \pm 9.03$ & $342.43 \pm 11.44$ \\
Group 3 & $224.02 \pm 11.38$ & $89.86 \pm 9.98^{* * *}$ \\
Group 4 & $223.77 \pm 8.03$ & $219.56 \pm 8.77$ \\
Group 5 & $226.48 \pm 9.28$ & $94.18 \pm 10.71^{* * *}$ \\
Group 6 & $228.92 \pm 11.38$ & $98.01 \pm 11.43^{* * *}$ \\
Group 7 & $224.82 \pm 12.99$ & $202.32 \pm 12.94$ \\
Group 8 & $221.64 \pm 10.30$ & $102.03 \pm 13.77^{* * *}$ \\
Group 9 & $224.31 \pm 9.03$ & $98.16 \pm 9.61^{* * *}$ \\
\hline
\end{tabular}

Data are represent as mean \pm SEM $(n=6)$ and one-way analysis of variance (ANOVA) followed by Dunnett test for multiple column comparison. ${ }^{*} P<0.05$, $* * P<0.01$ and $* * * P<0.001$ were considered to be less significant, significant and more significant when all groups were compared with control.

of EA and CP were found $75.100 \pm 0.265$ and $142.267 \pm 0.416$ in $\mathrm{mg}$ $\mathrm{AE} / 100 \mathrm{~g}$ respectively.

EA and CP suspensions were liquid in nature, characteristics odor and suspension texture. EA appeared olive green and CP was greenishbrown in color. $\mathrm{pH}$, dispersibility, flow rate and particle size of EA were 7.1, 2 Inversion, $2 \mathrm{ml} / \mathrm{sec}$ and 0.0431 , respectively and CP were 7.3, 2 Inversion, $2 \mathrm{ml} / \mathrm{sec}$ and 0.0424 , respectively. Table 1 shows the results for stability studies, no crystal formation was seen at different temperatures i.e. $4^{\circ} \mathrm{C}, 25^{\circ} \mathrm{C}$ and $47^{\circ} \mathrm{C}$.

EA and $\mathrm{CP}$ effervescent granules were solid, light green in color, characteristics odor and cylindrical texture. The angle of repose, bulk density, tapped density $\mathrm{C}$ index, $\mathrm{H}$ ratio and effervescent cessation time for EA were $17.223^{\circ}, 0.33,0.38,13.15,1.15$ and $2.50 \mathrm{~min}$, respectively and for $\mathrm{CP}$ were $13.495^{\circ}, 0.34,0.36,5.55,1.05$ and $2.27 \mathrm{~min}$, respectively.

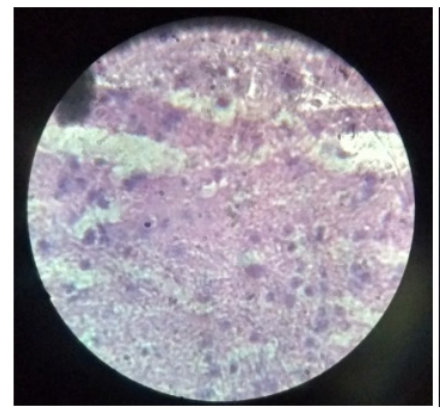

(a) Positive control

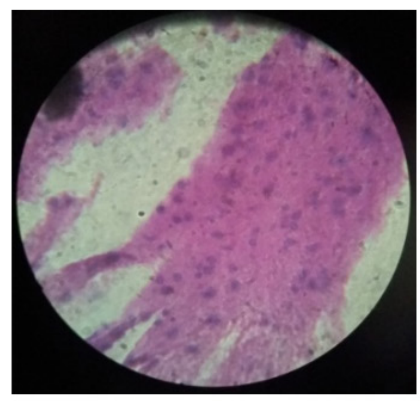

(c) EA suspension

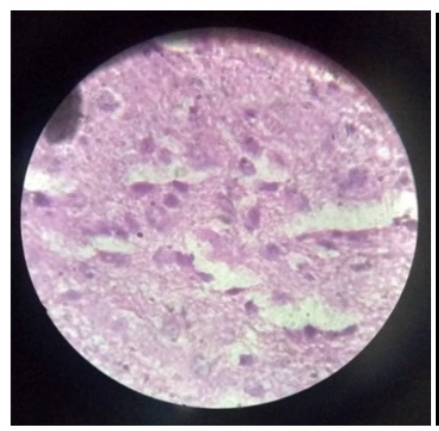

(e) EA Effervescent granules (f) CP Effervescent granules

Figure 2: Brain Histological study in rats (magnification 100X). In control group, no neuronal loss was observed (a). In scopolamine induced group, inflammation, erupted cytoplasm and neurodegeneration were found (b). In EA suspension group, remarkable improvement was observed(c). In CP suspension group, improvement was observed but little degeneration was also found (d). In EA effervescent granules group, cure for inflammation and cytoplasm were found (e). In CP effervescent granules group, cure but slight damage, degeneration of few neurons was found ( $f$ ). 
Table 4: Effect of EA and CP on AChE activity.

\begin{tabular}{cc}
\hline Groups & AChE Activity (Units/L) \\
\hline Group 1 & $8.55 \pm 0.30$ \\
Group 2 & $22.91 \pm 0.07$ \\
Group 3 & $15.17 \pm 0.29^{* * *}$ \\
Group 4 & $36.70 \pm 1.82$ \\
Group 5 & $19.10 \pm 1.51^{* * *}$ \\
Group 6 & $17.69 \pm 0.26^{* * *}$ \\
Group 7 & $35.27 \pm 0.28$ \\
Group 8 & $18.01 \pm 0.21^{* * *}$ \\
Group 9 & $14.36 \pm 0.57^{* * *}$ \\
\hline
\end{tabular}

Data are represent as mean \pm SEM $(n=6)$ and one-way analysis of variance (ANOVA) followed by Dunnett test for multiple column comparison. ${ }^{*} P<0.05$, ${ }^{* *} P<0.01$ and ${ }^{* *} P<0.001$ were considered to be less significant, significant and more significant when all groups were compared with control.

No clinical signs of toxicity and mortality were observed in animals. Thus, lower doses after an acute toxicity study were selected for behavioral studies.

Scopolamine raised the activity score of animals in 30 and $60 \mathrm{~min}$. Piracetam and the test drugs showed significant CNS depressant activity when compared with control; however; this depression was less with test drug than the standard group. Results from Table 2 show that herbal suspension and effervescent granules were more effective in depressing CNS activity in comparison to plant extracts of EA and CP. The plant's extracts and formulations were effective in reducing mean fall off time in comparison to the negative control group. The positive control group raised the fall off time, which was reduced by both the formulations of EA and CP significantly. Results from Table 3, both herbal suspension and effervescent granules were found equally effective in reducing CNS activity in comparison to the control group.

AChE activity was raised chronically with the administration of scopolamine. The test formulations were effective in reducing the activity of AChE in comparison to the control group. Piracetam showed significant activity i.e. 15.17 units/L. Results from Table 4, both the formulations of EA and CP reduced the activity of AChE in which effervescent granules of $\mathrm{CP}$ showed the highest reducing capability among all treated groups.

The histopathology of brain tissues after treatment with test drugs is shown in Figure 2. It was performed at 100X magnification. Neurons, glial cells and dendrites are shown in figures. White space shows the arachnoid mater. In control group, no neuronal loss was observed. Scopolamine caused lesion, inflammation, erupted cytoplasm and neurodegeneration in the brain which was healed by both EA and CP in comparison to the control group. In EA suspension group, remarkable improvement was observed(c). In CP suspension group, improvement was observed but little degeneration was also found (d). In EA effervescent granules group, cure for inflammation and cytoplasm were found (e). In CP effervescent granules group, cure but slight damage, degeneration of few neurons was found. Both formulations were effective in healing lesion present in brain tissues.

\section{DISCUSSION}

ACh play very important role in peripheral and central nervous systems both. In peripheral nervous system, it is responsible for the locomotor activity while in central nervous systems, it help in the formation of the memory. In brain, deficiency of ACh or depletion of ACh couse various neurodegenerative diseases in which $\mathrm{AD}$ is one of them. $\mathrm{AD}$, an irreversible neurodegenerative disorder primarily targeting elderly populations, affects approximately 36 million people worldwide. This illness is characterized by progressive neurodegenerative disorders, collapse of cognitive functions and formations of amyloid plaques and neurofibrillary tangles. The level of ACh is decrease due to AChE which affects the cognition and progressed with locomoter disfunctioning. Dementia is major symptom of AD patients. The inhibition of AChE has been one of the most used strategies for the treatment of $\mathrm{AD}$. The AChE inhibitors produce not only short-term symptomatic effects, but can also play a role in other pathological mechanisms of the disease (eg, formation of amyloid- $\beta$ plaques), which has renewed interest in the discovery of such inhibitors.

Dopamine controls the locomotor behavioral activity of the body by activating the mesolimbic dopaminergic pathway. ${ }^{33}$ The behavioral effects due to excitation of dopaminergic stimulation include enhanced locomotor activity, self-administration and more turning behavior. ${ }^{34}$ ACh also affects the locomotor activity due to nicotinic acetylcholine receptors present in the mesolimbic dopaminergic system. ${ }^{35}$ Scopolamine causes memory impairment and disturbed locomotor activity. ${ }^{36,37}$ Piracetam is a standard drug used for cognition enhancement that improves the functioning of $\mathrm{ACh}$ and implicated in the memory process. ${ }^{38}$ Rotarod and actophotometer experimental models are used to determine the motor coordination of rodents. This method is sensitive to evaluate cerebellar dysfunction. It is the due acceleration of dopamine level in the brain that can be easily discriminate with rats having striatal dopamine depletion show no motor incoordination. ${ }^{39,40}$ In the present study, EA and CP both are used which are varieties of shankhpushpi. Both these are traditionally claimed for memory enhancement. Ethanolic extracts of both EA and CP were prepared using Soxhlet apparatus method. Both are alkaloid in nature that's why total alkaloids contents were estimated using atropine as standard. The behavioral effects of EA and CP formulations were determined on rats. In this study locomotor activity using actophotometer and muscle relaxing property using rotarod were determined along with estimation of AChE inhibition by ellman's method. In our study, herbal suspension and effervescent granules both the formulations were significantly effective in actophotometer and rotarod methods of behavioral experimental models. Additionally, the formulations also decreased AChE activity to enhance cognition in animals. Both formulations of EA and CP restored the locomotor activity of rats. It may be due to cognition enhancement by the test drugs.

The efficacy of EA extract has already reported about the enhancement of cognition and behavioral response in animals against amnesia induced by scopolamine. ${ }^{27}$ However, the formulations of EA showed more significant results in comparison to extract. CP extract has shown efficacy in boosting memory and cognition, which is reported by several researchers. ${ }^{15,41}$ It elicits a significant effect in animal models by interacting with the dopaminergic, adrenergic and serotonergic systems in the body. ${ }^{42}$ The suspension of herbal extracts has been formulated to achieve good results in animal models. ${ }^{22,24,43,44}$ Effervescent granules of EA were also equally effective as a suspension to reduce fall off time in rota rode and activity score in actophotometer. ${ }^{45}$ Similar results were reported by another researcher regarding the efficacy of herbal effervescent granules in experimental animal models for other drugs. ${ }^{46,47}$

\section{CONCLUSION}

EA and CP suspension and effervescent granules showed a protective effect against scopolamine-induced locomotor impairment and degradation of ACh. It may be used as a sedative, mood enhancer and memory enhancer for neurodegenerative disorders after trials in human beings. 


\section{ACKNOWLEDGEMENT}

Authors are thankful to the Department of Pharmaceutical Sciences, Dr. Harisingh Gour University, Sagar (M.P). Financial assistance (SB/ EMEQ-376/2014) received from SERB, DST, Govt of India is gratefully acknowledged.

\section{CONFLICT OF INTEREST}

The authors declare no Conflict of interest.

\section{ABBREVIATIONS}

CP: Convolvulus pluricaulis; EA: Evolvulus alsinoides.

\section{REFERENCES}

1. Weller J, Budson A. Current understanding of Alzheimer's disease diagnosis and treatment. F1000 Res. 2018;1161.

2. Volicer L. Behavioral Problems and Dementia. Clin Geriatr Med. 2018;34(4):63751.

3. Anand A, Khurana P, Chawla J, Sharma N, Khurana N. Emerging treatments for the behavioral and psychological symptoms of dementia. CNS Spectr. 2018;23(6):361-9.

4. Feast A, Orrell M, Charlesworth G, Melunsky N, Poland F, Moniz-Cook E. Behavioural and psychological symptoms in dementia and the challenges for family carers: Systematic review. Br J Psychiatry. 2016;208(5):429-34

5. Lane CA, Hardy J, Schott JM. Alzheimer's disease. Eur J Neurol. 2018;25(1):5970.

6. Høgh P. Alzheimer's Disease. Ugeskr Laeger. 2017;179(12).

7. Tewari D, Stankiewicz AM, Mocan A, Sah AN, Tzvetkov NT, Huminiecki L, et al. Ethnopharmacological approaches for dementia therapy and significance of natural products and herbal drugs. Front Aging Neurosci. 2018;10(3):1-24.

8. Carotenuto A, Rea R, Traini E. The Effect of the association between donepezil and choline alphoscerate on behavioral disturbances in alzheimer's disease: Interim results of the ascomalva trial. J Alzheimers Dis. 2017;56(2):805-15.

9. Noufi P, Khoury R, Jeyakumar S, Grossberg GT. Use of cholinesterase inhibitors in non-alzheimer's dementias. Drugs Aging. 2019;36(8):719-31.

10. Mannangatti P, Naidu KN. Indian herbs for the treatment of neurodegenerative disease. Adv Neurobiol. 2016;12:323-36.

11. Kashima Y, Miyazawa M. Chemical composition and aroma evaluation of essential oils from Evolvulus alsinoides L. Chem Biodivers. 2014;11(3):396-407.

12. Austin DF. Evolvulus alsinoides (Convolvulaceae): An American herb in the old world. J Ethnopharmacol. 2008;117(2):185-98.

13. Yadav MK, Singh SK, Singh M. Neuroprotective activity of Evolvulus alsinoides and centella asiatica ethanolic extracts in scopolamine-induced amnesia in swiss albino mice. Maced J Med Sci. 2019;7(7):1059-66.

14. Kizhakke PA, Olakkaran S, Antony A, Tilagul KS, Hunasanahally PG. Convolvulus pluricaulis (Shankhapushpi) ameliorates human microtubule-associated protein tau (hMAP $\tau$ ) induced neurotoxicity in Alzheimer's disease Drosophila model. J Chem Neuroanat. 2019;95:115-22.

15. Agarwa P, Sharma B, Fatima A, Jain SK. An update on Ayurvedic herb Convolvulus pluricaulis Choisy. Asian Pac J Trop Biomed. 2014;4(3):245-52.

16. Rachitha P, Krupashree K, Jayashree GV. Chemical composition, antioxidant potential, macromolecule damage and neuroprotective activity of Convolvulus pluricaulis. J Tradit Complement Med. 2018;8(4):483-96.

17. Farooqui AA, Farooqui T, Madan A, Ong JH, Ong WY. Ayurvedic medicine for the treatment of dementia: Mechanistic aspects. Evid Based Complement Alternat Med. 2018;1-11.

18. Bauer RH. Age-dependent effects of scopolamine on avoidance, locomotor activity and rearing. Behav Brain Res. 1982;5(3):261-79.

19. Hernández-Vázquez F, Reyes-Guzmán C, Méndez M. Impact of a novel environment on alcohol-induced locomotor activity in Wistar rats. Alcohol. 2018;71:5-13.

20. Shams $S$, Seguin D, Facciol A, Chatterjee D, Gerlai R. Effect of social isolation on anxiety-related behaviors, cortisol and monoamines in adult zebrafish. Behav Neurosci. 2017;131(6):492-504.

21. John B, Sulaiman CT, George S, Reddy VRK. Spectrophotometric estimation of total alkaloids in selected justicia species. Int J Pharm Pharma Sci. 2014;6(5):647-8.

22. Srivastava S, Verma NK, Vishwakarma DK. Formulation and stability studies of herbal suspension of formulation and stability studies of herbal suspension. Innovare J Health Sci. 2017;5(3):2-4.

23. Garg A, Vishwavidyalaya RD, Gupta R, Sharma P, Garg A, Soni A, et al. Formulation and evaluation of herbal effervescent granules incorporated with Martynia annual extract. J Drug Discov Ther. 2013;1(5):54-7.

24. Mac DR, Camargo SS, Meyre-Silva C, Quintão NLM, Cechinel FV, Bresolin $\mathrm{TMB}$, et al. Development of an oral suspension containing dry extract of Aleurites moluccanus with anti-inflammatory activity. Rev Bras Farmacogn. 2016;26(1):68-76

25. Bostijn N, Renterghem JV, Dhondt W, Vervaet C, DeBeer T. A continuous manufacturing concept for a pharmaceutical oral suspension. Eur J Pharm Sci. 2018;123:576-83.

26. Zhang S, Wan Q, Xing Y, Ding J, Yang S, Sun W, et al. Formulation and evaluation of a novel oral oil-based suspension using micro-environmental ph-modifying solid dispersion. APS Pharm Sci Tech. 2019;20(2):75.

27. Nahata A, Patil UK, Dixit VK. Effect of Evolvulus alsinoides Linn on learning behavior and memory enhancement activity in rodents. Phytother Res. 2010;24(4):486-93.

28. Dews PB. The measurement of the influence of drugs on voluntary activity in mice. Br J Pharmacol Chemother. 1953;8(1):46-8.

29. Dunham NW, Miya TS. A note on a simple apparatus for detecting neurological deficit in rats and mice. J Am Pharm Assoc. 1957;46:208-9.

30. Ellman GL, Courtney KD, Andres V, Featherstone RM. A new and rapid colorimetric determination of acetylcholinesterase activity. Biochem Pharmacol. 1961;7(2):88-95

31. Topçu G, Kolak U, Öztürk M, Boga M, Hatipoglu SD, Bahadori F, et al. Investigation of anticholinesterase activity of a series of salvia extracts and the constituents of salvia staminea. Nat Prod J. 2013;3(1):3-9.

32. Ali AA, Khalil MG, Elariny HA, Abu-Elfotuh K. The role of mental and physical activities against development of Alzheimer's disease in socialized and isolated rats. Brain Disord Ther. 2017;6(3):1-17.

33. Garrett BE, Holtzman SG. Comparison of the effects of prototypical behavioral stimulants on locomotor activity and rotational behavior in rats. Pharmacol Biochem Behav. 1996;54(2):469-77.

34. Garrett BE, Griffiths RR. The role of dopamine in the behavioral effects of caffeine in animals and humans. Pharmacol Biochem Behav. 1997:57(3):533-41.

35. Kamens HM, Peck C, Garrity C, Gechlik A, Jenkins BC, Rajan A. a6ß2 nicotinic acetylcholine receptors influence locomotor activity and ethanol consumption. Alcohol. 2017;61:43-9.

36. Rabiei Z, Setorki M. Effect of hydroalcoholic Echium amoenum extract on scopolamine-induced learning and memory impairment in rats. Pharm Biol. 2018:56(1):672-7.

37. Hasegawa Y, Inoue T, Kawaminami S, Fujita M. Effects of scallop shell extract on scopolamine-induced memory impairment and MK801-induced locomotor activity. Asian Pac J Trop Med. 2016;9(7):662-7.

38. Winnicka K, Tomasiak M, Bielawska A. Piracetam--an old drug with novel properties?. Acta Poloniae Pharmaceutica. 2005;62(5):405-9.

39. Shiotsuki H, Yoshimi K, Shimo Y. A rotarod test for evaluation of motor skill learning. J Neurosci Methods. 2010;189(2):180-5.

40. Mirza R, Sharma B. Selective modulator of peroxisome proliferator-activated receptor- $\alpha$ protects propionic acid induced autism-like phenotypes in rats. Life Sci. 2018;214:106-17.

41. Malik J, Choudhary S, Kumar P. Protective effect of Convolvulus pluricaulis standardized extract and its fractions against 3-nitropropionic acid-induced neurotoxicity in rats. Pharm Biol. 2015;53(10):1448-57.

42. Dhingra D, Valecha R. Evaluation of the antidepressant-like activity of Convolvulus pluricaulis choisy in the mouse forced swim and tail suspension tests. Med Sci Monit. 2007;13(7):155-61.

43. Dandagi PM, Patil MB, Mastiholimath VS, Gadad AP, Dhumansure RH. Development and evaluation of hepatoprotective polyherbal formulation containing some indigenous medicinal plants. Indian J Pharm Sci. 2008;70(2):265-8

44. Sarkar BK, Maddi R, Devgan M. Development and evaluation of oral herbal formulations of lantana camara extract. J Pharm Biol. 2014;4(1):23-5.

45. David J, Backstedt DW, O'Keefe KJ, Salehpour K, Gerkin R. Tu1203 Effervescent granules are a safe, effective and cost-saving initial strategy in acute esophageal food impaction. Gastrointest Endosc. 2017;85(5):1.

46. Pandey P, Sharma P, Gupta R, Garg A, Shukla A, Nema N, et al. Formulation and evaluation of herbal effervescent granules incorporated with Martynia Annua extract. J Drug Discov Ther. 2013;1(5):54-7.

47. Abdoun S, Hassan TI, Gaber DA, Sharekh AE-. Antidepressant activity of $A$ hierochuntica L. Effervescent granules using forced swimming test. JIPBS. 2019;6(2):38-44

Article History: Submission Date : 11-09-2020; Revised Date : 20-10-2020; Acceptance Date : 12-11-2020

Cite this article: Jain G, Patil UK. Formulation, Characterization and Evaluation of Behavioral Effects of Suspension and Effervescent Granules of Evolvulus alsinoides Linn. and Convolvulus pluricaulis Choisy. Int. J. Pharm. Investigation, 2020;10(4):460-5. 